\title{
Authors' response to Shukla and Dixit
}

\author{
Rakesh Aggarwal ${ }^{1} \cdot$ Nithya Gogtay $^{2} \cdot$ Rajeev Kumar $^{3} \cdot$ Peush Sahni ${ }^{4} \cdot$ for Indian \\ Association of Medical Journal Editors
}

Published online: 18 August 2016

(C) Indian Society of Gastroenterology 2016

We thank Drs. Shukla and Dixit for their comments [1] on our recent editorial [2]. They list several factors that impede research on part of faculty members in medical institutions, including rules that do not permit them to guide research students for several years after joining as faculty, lack of resources for doing research, limited availability of time because of heavy clinical workload, access to journals, etc. We agree with them that, to improve the research output of faculty members in medical institutions around India, these issues too need attention, though our editorial, since it was written on behalf of the Indian Association of Medical Journal Editors, focused mainly on issues related to the publication process.

They go on to discuss some recent developments in the field of scholarly publication, namely (i) predatory journals, which we discussed in detail in our editorial and (ii) the increasing trend among journals of requiring the authors to pay publication fees. It is time that various stakeholders interested in improving the country's research output, including the Indian researchers, research and academic institutions, and the various funding agencies, discuss these issues. This discussion should help develop guidance for prospective authors on how to identify predatory journals and put in place mechanisms by which either the funding agencies or academic institutions could support payment of publication charges.

\section{References}

1. Shukla SK, Dixit VK. Publication for promotion in medical academia. Indian J Gastroenterol 2016;35. doi:10.1007/s12664-016-0689-1.

2. Aggarwal R, Gogtay N, Kumar R, Sahni P, for the Indian Association of Medical Journal Editors. Academic promotions and the revised Medical Council of India guidelines: need for a rethink. Indian J Gastroenterol 2016; 35: 3-6.
Rakesh Aggarwal editors@gmail.com

\footnotetext{
Indian Journal of Gastroenterology, Mumbai, India

2 Journal of Postgraduate Medicine, Mumbai, India

3 Indian Journal of Urology, New Delhi, India

4 The National Medical Journal of India, All India Institute of Medical Sciences, New Delhi 110 029, India
} 